\title{
Türkiye'de Sektörel Teknolojik Gelişmelerin Makroekonomi Üzerindeki Etkisi:İnşaat Sektöründe Yapay Zeka Kullanımına Yönelik Bir İnceleme
}

\author{
Ayça DOĞANER ${ }^{1}$
}

\section{Öz}

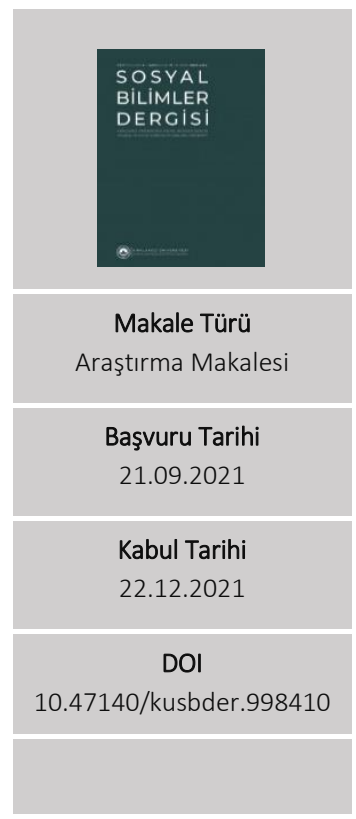

Inşaat sektörü ekonomi için oldukça önemli sektörlerden birisidir. Ülke ekonomisinde makro dengelere olumlu etkileriyle Gayri Safi Milli Hasılayı artırma, istihdam yaratma, sosyo-ekonomik refahı geliştirme ile ekonomik kalkınmayı sağlamada etkindir. Özellikle lokomotif sektörlerden birisi olma özelliğiyle ve yüksek işgücü kapasitesiyle, diğer ana ve alt sektörlerin de büyümesine ve gelişmesine sağladığı katkılarla ekonomiyi en çok etkileyen sektörlerden birisidir. Son dönemlerde yaşanan teknolojik gelişmelerin ve Endüstri 4.0 gibi kavramların faydalarının oldukça konuşulduğu değerlendirildiğinde, inşaat sektörünün de bu gelişmelerin dışında kalmaması gerektiği açıktır. Bu amaçlarla bu çalışmada son günlerde oldukça güncel olan yapay zeka uygulamalarının inşaat sektörü üzerindeki etkileri ekonomik boyutu ile ele alınmıştır. İstanbul'da faaliyet gösteren ve İstanbul Ticaret Odası'na kayıtlı olan inşaat firmaları üzerinde yapay zekanın inşaat sektörüne etkisi konusunda hazırlanan anket çalışması yapılarak, elde edilen verilere faktör analizi uygulanmıştır. Çalışmanın sonucunda yapay zeka modellerinin inşaat sektöründe uygulanmasıyla daha hızlı, verimli, hatasız sonuçlar elde edilebilecek ve maliyet ve zamandan tasarruf sağlanacağı tespit edilmiştir. Bu nedenle inşaat sektöründe yapay zekanın kullanılmasının yaygınlaştırılmasının birçok açıdan faydalı olduğu görülmektedir.

Anahtar sözcükler: yapay zeka, makine öğrenmesi, inşaat sektörü, teknolojik gelişme, makroekonomi

\footnotetext{
${ }^{1}$ Sorumlu Yazar:Dr., İstanbul Ticaret Odası, E-posta: ayca.doganer@gmail.com, https://orcid.org/0000-00034277-9326
} 


\title{
The Effect Of Sectoral Technological Developments on Macroeconomic in Turkey: A Review On The Use Of Artifical Intelligence In The Construction Sector
}

\author{
Ayça DOĞANER ${ }^{2}$
}

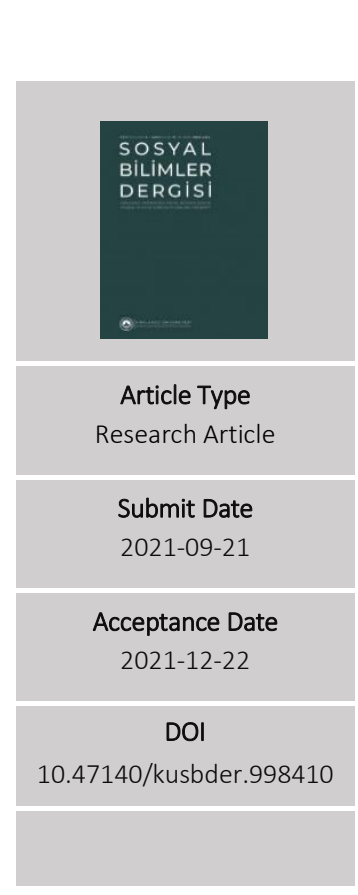

\begin{abstract}
The construction sector is one of the most important sectors fort he economy. It is effective in increasing Gross National Product, creating employment, improving socio-economic welfare and providing economic development with its positive effects on the macro balances in the country's ecenomy. It is one of the sectors that most affect the economy, especially with its feature of being one of the locomotive sectors and its high workforce capacity, and its contributions to the growth and development of other main and subsectors. Considering that the benefits of recent technological developments and concepts such as Industry 4.0 have been discussed, it is clear that the construction industry should not be left out of these developments. For these purposes, in the study, the effects of artifical intelligence applications, which are quite up-todate in recent days, on the construction sector are discussed with their ecenomic dimension. A survey study prepared on the effect of artifical intelligence on the construction sector companies operating in Istanbul and registered with the Istanbul Chamber of Commerce was conducted and factor analysis was applied to the obtained data. As a result of the study, it has been determined that faster, more efficient, error-free results can be obtained and cost and time savings will be achieved by applying artifical intelligence models in the construction industry. For this reason, it has seen that widespread use of artifical intelligence in the construction sector is benefical in many ways.
\end{abstract}

Key words: artificial intelligence, machine learning, contruction sector, technological development, macroeconomy

\footnotetext{
${ }^{2}$ Corresponding Author: PhD., Istanbul Chamber of Commerce, E-mail: ayca.doganer@gmail.com, https://orcid.org/0000-0003-4277-9326
} 


\section{Giriş}

Teknolojik ilerleme ile günümüzde yalnızca insanların yapabileceğini düşündüğümüz işlerin değişime uğrayarak aynı işlerin insanlardan daha iyi yapılabileceği bir dijital çağın gelecekte karşımıza çıkacağı beklentisini taşımaktayız. Otomasyon uygulamaları, yapay zeka ve dijital teknolojilerin her geçen gün hızla geliştiği, bu süreçte insan müdahalesine olan ihtiyacın azalarak ya da tamamen ortadan kaldırılarak süreçlerin ilerletileceği beklenmektedir (McKinsey, 2020:9,10). Teknolojik ilerleme, kişi başına düşen Gayri Safi Yurtiçi Hasıla (GSYiH) artışının ana itici gücüdür. Aynı zamanda verimlilik artışına da neden olmaktadır. 20. yüzyılın sonlarında bilgisayarların ve internetin ortaya çıkışıyla gelişen teknoloji, üretkenliği artırmış, ekonomileri dönüştürmüş, toplumsal ve çevresel değerleri daha da önemli hale getirmiştir.

Yapay zeka ekonomik olarak gelişime olumlu anlamda katkılar sağlayacaktır. PricewaterhouseCoopers-PwC tarafından yapılan Küresel Yapay Zeka çalışmasında, küresel GSYiH'de 2030 yılına kadar yapay zeka sayesinde tahmini 15,7 trilyon dolar yani yaklaşık \%26 oranında bir artış gerçekleşeceği belirtilmektedir. Söz konusu rakam hem Çin hem de Hindistan'ın mevcut GSYiH'den daha büyük bir orana tekabül etmektedir. Yapay zekanın küresel ekonominin üretkenliğini ve GSYiH potansiyelini değiştirebileceği, ülkelerin söz konusu teknolojilere stratejik yatırımlar gerçekleştirmesi gerektiği de ayrıca belirtilmektedir. Bazı sektörler ve piyasalar için yapay zeka alanında gelişimlerin erken aşamasında olduğu, bunun özellikle pazar lideri olmak adına bir fırsat olarak değerlendirilebileceği de göz önünde bulundurulmalıdır (PricewaterhouseCoopers, 2017:s.3).

Yapay zeka, bilgisayarların insan gibi davranışlar göstermesi olarak tanımlanmaktadır. Bu doğrultuda yapay zeka denildiğinde, sayısal mantık yürütme, analitik düşünme, hareket etme, ses algılama ve konuşma özelliklerine sahip olma gibi unsurların bir arada bulunduğu yazılımsal ve donanımsal sistemler akla gelmektedir.

2020 yılında inşaat sektörünün GSYiH içindeki payı \%5,4 olmuştur. Gayrimenkulle alakalı aktivitelerin payı ise \%6,2 oranındadır. Ayrıca bağlantılı olduğu ve sayısı 200'den fazla olan sektörleri de dahil ettiğimizde ekonomi içerisindeki payının \%30'lara ulaştığı tahmin edilmektedir. İstihdamdaki payı da \%5,7 olarak belirtilmektedir (TMB, 2021:s.19,20). Bu veriler inşaat sektörü ve bağlantılı sektörlerin ekonomi üzerindeki önemini göstermektedir. Ekonomi içerisinde bu kadar önemli olan bir sektörün gelişmesi ve büyümesi için verimlilik artışlarının yapay zeka ile desteklenmesi sağlanmalıdır.

Bu çalışmada İstanbul'da faaliyet gösteren inşaat firmalarının yapay zekanın inşaat sektöründe kullanımının ekonomiye olan yansımaları hakkındaki görüşlerinin incelenmesi amaçlanmıştır. Bu kapsamda İstanbul Ticaret Odası'na kayıtlı olan inşaat sektöründe 
faaliyet gösteren firmalar ile görüşülmesi planlanmış, böylelikle sektörde birebir faaliyet gösteren firmaların bu konuda neler düşündüğü de ortaya çıkartılmak istenmiştir.

\section{Yapay Zeka}

Yapay zekanın (Al-“Artifical Intelligence") ne anlama geldiğini gözden geçirmek gerektiğinde, öncelikle kelime dizisinin kökeninde olan zeka kelimesine dikkat etmek gerekmektedir. Intelligence kelimesi Latince'den gelmekte olup, bir seçim yapmak anlamına gelmektedir. Bu nedenle "intelligence" kelimesi, rasyonel bir anlayışa ulaşmak için nesneler ve gerçekleri anlamak ve onlar arasındaki bağlantıları keşfetmeyi mümkün kılan zihinsel yetkinlik olarak tanımlanmaktadır. Bu, yeni durumları anlamayı ve adapte olmayı mümkün kılar, intelligence yani zeka bir hedefe ulaşmak için bilgiyi işleme yeteneği olarak gibi de görülebilir (Lafrate, 2018: 1,2).

Yapay zeka (Al) kavramının ilk kez ortaya çıkışına bakıldığında, bazı kaynaklara göre 1955, bazılarına göre ise 1956 yılları dile getirilmektedir. Dartmouth kolejinde yapılan atölye çalışmalarında yeni bir araştırma disiplini olarak kabul edildiği ve 1955 yılında John McCarthy tarafından proje başvurusunda bulunulduğu ifade edilmektedir. Bu süre zarfından beri bilim dünyası tarafından farklı açıklamalar ve çalışmalar yapıırken, yapay zekanın hem yararlarından hem de zararlarından bahsedilmektedir (Değirmenci ve Aydın, 2018:6).

Son yıllarda, Endüstri 4.0, üretim firmaları ve servis sistemleri büyük ilgi görmektedir. Öte yandan, Endüstri 4.0'ın kesin bir tanımı bulunmamakta ve doğal olarak, ortaya çıkan teknolojilerin kesin bir kullanımı da bulunmamaktadır. Temel olarak Endüstri 4.0, katma değerli ağların kurulmasını sağlayan sistemler olan üretim tesislerinin, tedarik zincirlerinin ve hizmetlerin entegrasyonundan oluşmaktadır. Böylece, büyük veri analitiği, özerk (kendi kendini idare eden) robotlar, siber fiziksel altyapı, simülasyon, yatay ve dikey entegrasyon, Endüstriyel İnternet, bulut sistemleri, ek üretim ve artırılmış gerçeklik gibi yeni geliştirilen teknolojilere başarılı bir adaptasyon için gereklidir (Salkin ve diğerleri, 2017: 5,6).

Yapay zeka (AI) insanlar tarafından bir yapay olgu gibi geliştirilen bir zeka olarak belirtilmektedir. Alan Turing'in ünlü testinin (1950) [sıradan (aptalca) insanları, diyaloğun diğer ucunun bir insan tarafından mı yoksa bir bilgisayar tarafından mı yürütüldüğü konusunda kandırma yeteneği] talep ettiği istihbarat seviyesi Al araştırmacılarının neyi amaçladıklarının bir göstergesidir. Böyle bir Al'nin kesinlikle teknolojiyi ve ekonomiyi dönüştüreceği belirtilmektedir. Bu yolla, çok sayıda insan kaçakçılığı ve evrak işi otomatikleşebilir. Bilgisayarlar evrensel olduğundan, programlar zahmetsizce bir sistemden diğerine kopyalanabilir (fikri mülkiyet haklarından endişe duyulur) ve eğer ciddi bir Al gelişirse, bürokratik kural uygulamaları, tıbbi teşhis, araştırma yardımı, üretim kontrolü vb. için işgücü tasarrufları sağlanabilir (Korn ve Nicholson, 2011, s.3). 
Bir yapay zeka (AI) sistemi, gerçek veya sanal ortamları etkileyen tahminler, öneriler veya kararlar verilen bir dizi insan tarafından tanımlanmış hedefler için makine tabanlı bir sistemdir. Bunu, makine ve / veya insan bazlı girişleri kullanarak yapmaktadır. Yapay zeka, ekonomileri yeniden şekillendirmekte, verimlilik kazancı üretmeyi, verimliliği arttırmayı ve maliyetleri düşürmeyi vaat etmektedir. Daha iyi yaşamlara katkıda bulunmakta, insanların daha iyi tahminler yapmalarına ve daha bilinçli kararlar vermelerine yardımcı olmaktadır. Bununla birlikte, bu teknolojiler halen başlangıç aşamasındadır ve AI'nın küresel zorlukları ele alma, inovasyonu ve büyümeyi destekleme konusunda çok fazla vaadi bulunmaktadır. Al'nın etkileri toplumumuza nüfuz ettiğinden, dönüşümsel gücünün insanların ve gezegenin hizmetine sunulması gerekmektedir (Ekonomik Kalkınma ve İşbirliği Örgütü, 2019: 3,24-25).

Çoğu Al sistemi, verilerin, işlemlerin ve kontrolün standart işlemsel bileşenleri arasında az çok katı bir ayrım gösterir. Diğer bir deyişle, eğer bu sistemler uygun bir seviyede tanımlanırsa, bazıları genellikle tüm küresel kontrol stratejisinin kontrolü altında, iyi tanımlanmış belirli işlemlerle manipüle edilen bir global veritabanı olarak adlandırılabilecek merkezi bir varlık tanımlanabilir (Nilsson, 2014:17).

\section{inşaat sektöründe yapay zeka}

İnsanlığın başlangıcından beri teknolojinin var olduğu, çarkın 4.000 yıldan daha uzun bir süre önce icat edildiği ve Mısırlıların piramitleri inşa ederken nakliyede devrim yarattığı düşünülmektedir. 21. yüzyılda, teknolojik ilerleme her zamankinden daha da hızlıdır. Yapay zeka (AI), küresel ekonomilerde giderek artan bir rol oynamakta ve yeni bir sanayi devriminden daha azını yaratmamaktadır. İnşaat sektörü bu yıkıcı değişime karşı değildir, bu açıdan hem zorlukları hem de fırsatları ortaya çıkarmaktadır. Yapı malzemeleri, yüzlerce yıldır halatlar ve makaralarla kaldırılmıştır. Ekskavatörler, bir asırdan fazla bir süre önce kas ve kürekleri birçok amaç için değiştirmiştir. Fakat Al farklı bir düzendedir. Al, bilgisayar sistemlerinin normalde akıllı insan müdahalesi gerektiren işleri yapabilme becerisi olarak tanımlanmakta olup, bu robotların ötesine geçen çok geniş bir tanımdır (Currie\&Brown, 2018).

Reports And Data tarafından yayınlanan bir rapora göre, yapı pazarındaki küresel yapay zekanın (Al) 2026'ya kadar 4,51 Milyar Dolar'a ulaşması beklenmektedir. İnşaat sektörünün zaman ve maliyet tüketimi gereklilikleriyle birlikte kalitenin ve güvenliğin kolay azaltılması, pazarın büyümesini hızlandıracaktır. Yapay zeka inşaat maliyetlerini birçok yönden azaltmaya yardımcı olabilir. Sanal gerçeklik kullanımı ve mini robotların inşaatı devam eden işleri takip etmek için yapım aşamasında olan binalara yerleştirmesi gibi hususlar sayılabilir. Al, günümüzde modern binalarda elektrik ve sıhhi tesisat sistemlerinin güzergahlarını tasarlamak için kullanılmaktadır. Yapay zeka, iş yerlerinde 
güvenlik sistemlerinin gelişmesi için de faydalı olup, tehlike ve kaza risklerini azaltır. Teknoloji, pek çok firma tarafından sahadaki makine, işçi ve nesnelerin gerçek zamanlı etkileşimlerini takip etmek ve potansiyel güvenlik sorunları, verimlilik sorunları ve inşaat hataları hakkında denetçileri uyarmak için kullanılmaktadır. Yapay zekanın ayrıca insan işgücünü azaltması, pahalı hataları azaltması, şantiye yaralanmalarını azaltması ve bina operasyonlarını daha verimli hale getirmesi beklenmektedir (Globalnewswire, 2019).

İnşaat sektörü dijital devrime nüfuz eden bir aykırılık değildir. Bu sektör bir tesisin yaşam döngüsü boyunca çeşitli disiplinlerden kaynaklanan önemli verilerle ilgilenmektedir (Bilal ve diğerleri, 2016:2).

Tüm bu açıklamalar değerlendirildiğinde, yapay zeka ve uygulamalarının maliyeti ya da ekonomiye katkıları da oldukça yüksek oranlarda olacaktır. İnşaat sektörünün bu denli yüksek katma değerinin olması sektörde aktif rol oynayacak olan yapay zeka çalışmalarının finansal boyutunun da önemli olduğunu kanıtlamaktadır. Bu çalışmada istatistiksel olarak yapay zeka uygulamalarına inşaat firmalarının bakış açısını belirlemek, finansmanını ve yansımaları değerlendirebilmek amacıyla 121 firma ile gerçekleştirilen anket çalışması neticesinde ulaşılan verilere faktör analizi uygulanmıştır.

Faktör analizi, birbirleriyle ilişkili olan değişkenleri, az sayıda bağımsız değişken kümeleri elde etmek amacıyla değiştirerek kullanan bir tekniktir. Birden fazla değişkenin birkaç kümeye ya da boyuta indirilmesi olarak da nitelendirilebilir. Bu kümelerden veya boyutlardan her birine faktör adı verilmektedir. Faktör analizinin inceleme alanı değişkenlerin birbirleriyle olan karşılıklı ilişkileridir. Bu şekilde, değişkenlerin daha anlamlı ve özetlenmiş bir şekilde oluşturulmasını sağlamaktadır. Analiz edilecek olan veri grubundaki ilişkilerin ortak hangi faktörler içinde tanımlanacağı hakkında basit açıklamalarda bulunmaktadır (Bayram, 2015, 199). Faktör analizinde amaçlanan değişken sayısının azaltılması ve değişkenler arasındaki ilişkilerin ortaya çıkartılmasıdır. Bunun sonucunda ise değişkenler sınıflandırılmaktadır.

Literatürde, inşaat sektöründe yapay zeka uygulamalarına yönelik çok sayıda çalışma bulunmamaktadır. Yapay zeka ile ilgili çalışmalar ise literatürde son yıllarda oldukça yer bulmaya başlamıştır. Bu çalışma Faktör Analizi ile İstanbul'da faaliyet gösteren inşaat firmalarının yapay zeka uygulamalarına bakış açısı ve inşaat sektöründe yapay zeka kullanılması durumunda ekonomiye yönelik etkilerin neler olabileceğini değerlendiren ilk çalışmalardan bir tanesidir.

\section{Yöntem}

Araştırmanın verilerine, İstanbul Ticaret Odası'na kayıtlı olan inşaat firmalarına gerçekleştirilen anket formu ile ulaşılmıştır. Anket formunu (11 soru) katılımcılardan 121 
kişi yanıtlamıştır. Anket soruları katılımcıların e-posta bilgilerine gönderilerek, alınan cevaplar neticesinde sonuçlara ulaşılmıştır.

Anket formunda firma ismi, kişi ismi, yaş aralığı, eğitim durumu, firmanın ana faaliyet alanı, firmadaki pozisyon bilgisinin sorulmasının yanı sıra yapay zeka hakkında bir takım sorular sorulmuştur. Ayrıca, katılımcıların yapay zeka hakkındaki görüşlerinin detaylı alınması amacıyla oluşturulan sorularda, soruların ölçeği için "En az" ile "En çok" arasında 5 seçenekli cevap dereceleri olan "Likert" ölçeği kullanılmıştır. Likert tipi soruların içerdiği seçenekler, araştırılması yapılan konu ile ilgili tutum veya görüş içeren bir ifade ve ifadeye katılım düzeyini belirtmektedir. Bu nedenle, Likert tipi sorularda iki aşırı uç arasında yer alan birden çok seçenek sunularak katılım düzeyi belirlenmektedir. Analizin yapılması sürecinde bu seçenekler derecelerine göre birer sayısal değer verilerek kodlanmaktadır. Bu şekilde nitel veri, nicel veriye dönüştürülmektedir (Turan ve diğerleri, 2015: 188)

Araştırma sorularında genel eğilim belirlenmeye çalışılmıştır. Bu nedenle tuzak sorular bulunmamaktadır. Anket formu sonucunda elde edilen verilere faktör analizi uygulanmıştır.

Faktör analizinin en temel varsayımı değişkenler arasındaki korelasyon matrisinin birim matristen farklı olması durumudur. Eğer korelasyon matrisi birim matris ise boyutlar indirgenememekte ve faktörler elde edilememektedir. Yani, ilgilenilen değişkenler arasında hiçbir şekilde anlamlı korelasyonlar bulunmamaktadır. Bu nedenle, korelasyon matrisinin birim matrise olan eşitliği ölçülmelidir.

Söz konusu sıfır hipotezi Bartlett küresellik testi ile test edilmektedir. Hipotezin reddedilmesi verilerin faktör analizi yapılmasına uygundur anlamına gelmektedir (Mert, 2016:113). Verilerin faktör analizine uygunluğunu ölçmek için kullanılan bir diğer istatistik de Kaiser-Meyer-Olkin (KMO) istatistiğidir. Değişkenler arasındaki korelasyon katsayılarının kısmi korelasyon katsayılarına oranlanması sonucunda elde edilmektedir. 0 ve 1 sayılarının aralığında yer almaktadır. KMO değeri 1'e yakınsa verilerin faktör analizi için uygun olduğu anlamına gelmektedir. 0.5'in altında olan KMO değeri ise verilerin faktör analizine uygun olmadığı anlamına gelmektedir. Bu nedenle öncelikle Bartlett küresellik testi ve KMO değerinin sonuçlarının incelenmesi ve verilerin faktör analizine uygun olup olmadığı değerlendirilmesi yapılmalıdır (Mert, 2016:113). Faktör analizinde 4 adet temel aşama bulunmaktadır. Bu aşamalar (Kalaycı, 2016:321-323);

- Veri setinin faktör analizine uygunluğunun saptanması aşaması: Veri setinin faktör analizine uygunluğunun saptanması da 3 aşamada gerçekleştirilmektedir. Bu aşamalar, korelasyon matrisinin oluşturulması, Bartlett testinin yapılması ve KaiserMeyer-Olkin (KMO) testinin yapılmasıdır. 
- Faktörlerin elde edilmesi aşaması: Faktörlerin elde edilmesi aşamasında, değişkenler arasındaki ilişkilerin temsil edilmesinde en yüksek dereceye sahip olan az sayıda faktörün bulunması hedeflenmektedir.

- Faktörlerin rotasyonu aşaması: Faktörlerin rotasyonu aşamasında, isimlendirilebilir ve yorumlanabilir faktörlerin elde edilmesi hedeflenmektedir.

- Faktörlerin isimlendirilmesi aşaması: Faktörlerin isimlendirilmesi aşamasında, ilgili bilgiler SPSS çıktıları ile yorumlanmaktadır.

\section{Bulgular}

Bu çalışmada anket formundan elde edilen verilere faktör analizi uygulanmıştır. SPSS 20 programının kullanıldığı çalışmada katılımcılara, yapay zekanın inşaat sektörünün geleceğini nasıl etkileyeceği, yapay zeka ve makine öğrenmesinin inşaat sektöründe kullanılıp kullanılamayacağını içeren maddelerde belirtilen seçeneklerden birisinin seçilmesi, yapay zeka ile ilgili görüşler, yapay zeka ve makine öğrenmesi modellerinin inşaat sektöründe uygulanması halinde gerçekleşecekler ve maliyet açısından değerlendirme yapıldığında yapay zekanın inşaat sektöründe en çok hangi alanı etkileyeceği sorularına önem sırasına göre belirlemeleri talep edilmiştir. Anket formuna "sizin için en uygun gelen seçeneği işaretleyiniz" cümlesi eklenmiş olduğundan, bir katılımcı birden çok seçeneği işaretleyememiştir.

Anket formunda Soru 9'da yapay zeka ile ilgili görüşler ölçülmeye çalışılmıştır. Bu kapsamda, KMO testi ve Barlett Analizi sonuçları Tablo 2' de gösterilmektedir.

Tablo 2. KMO ve Bartlett Testi

\begin{tabular}{lcc}
\hline \multicolumn{2}{c}{ Kaiser-Meyer-Olkin Measure Sampling } & Adequacy \\
& Approx.Chi-Square & .817 \\
\cline { 2 - 3 } $\begin{array}{l}\text { Bartlett's Test of } \\
\text { Sphericity }\end{array}$ & Df & 357.497 \\
\cline { 2 - 3 } & Sig. & 28 \\
\hline
\end{tabular}

Tablo 3. Güvenilirlik Analizi

\begin{tabular}{lcc}
\hline $\begin{array}{l}\text { Cronbach's Alpha Based on } \\
\text { Standarized Items }\end{array}$ & $\begin{array}{c}\text { N of } \\
\text { Items }\end{array}$ & Cronbach's Alfa \\
\hline .846 & 8 & .846 \\
\hline
\end{tabular}

KMO (Kaiser-Mayer-Olkin) testi ile araştırma örnekleme yeterliliği ölçülmektedir. Söz konusu test ile örneklem büyüklüğü sonuçları bulunmaktadır. Faktör analizi uygulamalarının yapılması için söz konusu oranın 0.50'den büyük olması beklenmektedir. Barlett analizinin oranlarının da O’a yakın çıkması anlamlı sonuçları işaret etmektedir. Aynı 
zamanda ki-kare değerinin istatistiğinin de anlamlı çıkması, araştırma verilerinin uygun bir şekilde yapılandırıldığını göstermektedir (Büyüköztürk: 2002, 479).

Tablo 2'de görüldüğü üzere, KMO testi 0.817 çıkmıştır. Bu sonuç analiz için iyi bir sonuçtur. 0.817>0.60 olduğundan veri setinin faktör analizi için uygun olduğu görülmektedir. Barlett analizinde de $p<0.05$ olmalıdır. Bu koşul da sağlanmaktadır. Veriler faktör analizi için uygundur. Bu istatistik testlerinin faktör analize uygun çıkmış olması nedeniyle, değişkenler arasında korelasyonların yüksek olduğu anlaşılmaktadır. Faktör sayısının belirlenmesi için "Açıklanan Toplam Varyans" yöntemi kullanılmaktadır.

Tablo 3’te görüldüğü üzere, Cronbach's Alfa değeri ise 0.846 çıkmıştır. Bu değer yüksek derecede güvenilir ölçek olarak nitelendirilmektedir.

Tablo 4. Anti-Images Matrisleri

\begin{tabular}{lcccc}
\hline & & S9A & S9D & S9F \\
\hline \multirow{3}{*}{$\begin{array}{l}\text { Anti-image } \\
\text { Covariance }\end{array}$} & S9A & .687 & -.133 & -.141 \\
\cline { 2 - 5 } & S9D & 0.35 & -.151 & -.130 \\
\cline { 2 - 5 } & S9F & -.141 & -.012 & .551 \\
\hline \multirow{3}{*}{$\begin{array}{l}\text { Anti-image } \\
\text { Correlation }\end{array}$} & S9A & $.795^{\mathrm{a}}$ & -.262 & -.229 \\
\cline { 2 - 5 } & $\mathrm{S} 9 \mathrm{D}$ & -.262 & $.823^{\mathrm{a}}$ & -.027 \\
\cline { 2 - 5 } & $\mathrm{S} 9 \mathrm{~F}$ & -.229 & -.027 & $.874^{\mathrm{a}}$ \\
\hline
\end{tabular}

Tablo 4'te görüleceği üzere, oluşturulan anti-image correlation matrislerinde bileşenlerin örneklem uygunluğu ölçütünün kabul edilebilirlik sınırı olan 0.5 değerinden yüksek olduğu gözlemlenmektedir.

Tablo 5. Ortak Varyans Tablosu

\begin{tabular}{lcc}
\hline & Initial & Extraction \\
\hline S9A & 1.000 & .702 \\
\hline S9D & 1.000 & .710 \\
\hline S9F & 1.000 & .615 \\
\hline
\end{tabular}

Tablo 5'te, her bir faktörün toplam faktörün ne kadarını etkilediği gösterilmektedir. Bu tabloda yer alan "Extraction" değerlerinin, 30 değerinin üzerinde olması beklenmektedir. "Iş̧ ve işçi güvenliğine olumlu etkileri var" faktörü \%71 oranı ile toplam faktörü şekillendirmede en çok etkisi olan faktördür. 
DOĞANER, Türkiye'de Sektörel Teknolojik Gelişmelerin Makroekonomi Üzerindeki Etkisi..., 55 -76

Tablo 6. Özdeğer İstatistiğine Bağlı Faktör Sayısı ve Açıklanan Varyans Yüzdesi

\begin{tabular}{|c|c|c|c|c|c|c|c|c|c|}
\hline \multirow{2}{*}{ Faktörler } & \multicolumn{3}{|c|}{ Initial Eigenvalues } & \multicolumn{3}{|c|}{$\begin{array}{l}\text { Extraction Sums of Squared } \\
\text { Loandings }\end{array}$} & \multicolumn{3}{|c|}{$\begin{array}{l}\text { Rotation Sums of Squared } \\
\text { Loandings }\end{array}$} \\
\hline & Toplam & $\begin{array}{c}(\%) \\
\text { Varyans }\end{array}$ & $\begin{array}{l}\text { Birikimli } \\
\text { (\%) }\end{array}$ & Toplam & $\begin{array}{c}\text { (\%) } \\
\text { Varyans }\end{array}$ & $\begin{array}{l}\text { Birikimli } \\
\text { (\%) }\end{array}$ & Toplam & $\begin{array}{c}\text { (\%) } \\
\text { Varyans }\end{array}$ & $\begin{array}{l}\text { Birikimli } \\
\text { (\%) }\end{array}$ \\
\hline 1 & 3.906 & 48.822 & 48.822 & 3.906 & 48.822 & 48.822 & 2.818 & 35.231 & 35.231 \\
\hline 2 & 1.008 & 12.603 & 61.425 & 1.008 & 12.603 & 61.425 & 2.096 & 26.194 & 61.425 \\
\hline 3 & .838 & 10.480 & 71.905 & & & & & & \\
\hline 4 & .636 & 7.946 & 79.851 & & & & & & \\
\hline 5 & .561 & 7.018 & 86.869 & & & & & & \\
\hline 6 & .482 & 6.021 & 92.890 & & & & & & \\
\hline 7 & .318 & 3.975 & 96.865 & & & & & & \\
\hline 8 & .251 & 3.135 & 100.00 & & & & & & \\
\hline
\end{tabular}

Extraction Method: Principal Component Analiz

Birikimli (\%) sütununda faktörlerin yüzde kaç açıkladığı verilmektedir. Tablo 6'da toplam sütununda yer alan ve özdeğeri 1'den büyük olan faktörler, faktör sayısı olmaktadır. Tablo 6'da verilen değerlerden, faktör sayısının 2 olduğu görülmektedir. 2 adet faktörün varyansa yaptığı katkı \%61.425 oranındadır.

Tablo 7. Faktör Matrisia

\begin{tabular}{lcc} 
& \multicolumn{2}{c}{ Faktörler } \\
\cline { 2 - 3 } & 1 & 2 \\
\hline S9D & .730 & \\
\hline S9C & .711 & \\
\hline S9A & .626 & .445 \\
\hline S9F & .576 & -.423 \\
\hline S9G & .561 & .622 \\
\hline
\end{tabular}

Extraction Method: Principal Component Analiz. a. 2 components extracted

Tablo 8. Döndürülmüş Faktör Matrisi

\begin{tabular}{lcc} 
& \multicolumn{2}{c}{ Faktörler } \\
\cline { 2 - 3 } & 1 & 2 \\
\hline S9E & .747 & \\
\hline S9C & .733 & \\
\hline S9F & .449 & .643 \\
\hline S9D & .675 & .504 \\
\hline S9G & & .835 \\
\hline S9A & & .735 \\
\hline
\end{tabular}

Extraction Method: Principal Component Analiz. Rotation Method:Varimax with Kaiser Normalization. a. Rotation converged in 3 iterations 
Tablo 9. Component Transformation Matrix

\begin{tabular}{lcc}
\hline Faktörler & 1 & 2 \\
\hline 1 & .790 & .613 \\
\hline 2 & -.613 & .790 \\
\hline $\begin{array}{l}\text { Extraction Method: Principal Component Analysis. Rotation Method:Varimax with } \\
\text { Kaiser Normalization. }\end{array}$ & \\
\hline
\end{tabular}

Anket formunda soru 10'da katılımcılara yapay zeka ve makine öğrenmesi modellerinin inşaat sektöründe uygulanması halinde gerçekleşeceklerin neler olabileceği sorulmuştur. Bu kapsamda, KMO testi ve Barlett Analizi sonuçları Tablo 10'da gösterilmektedir.

Tablo 10. KMO ve Bartlett Testi

\begin{tabular}{llc}
\hline \multirow{2}{*}{ Kaiser-Meyer-Olkin Measure Sampling Adequac } & .927 \\
\hline \multirow{3}{*}{$\begin{array}{llc}\text { Bartlett's Test } \\
\text { of Sphericity }\end{array}$} & Approx.Chi-Square & 781.296 \\
\cline { 2 - 3 } & Sf & 36 \\
\cline { 2 - 3 } & Sig. & .000 \\
\hline
\end{tabular}

Tablo 11. Güvenilirlik Analizi

\begin{tabular}{lcc}
\hline $\begin{array}{l}\text { Cronbach's Alpha Based on } \\
\text { Standarized Items }\end{array}$ & $\begin{array}{c}\text { N of } \\
\text { Items }\end{array}$ & Cronbach's Alfa \\
\hline .929 & 9 & .928 \\
\hline
\end{tabular}

Tablo 10'da görüldüğü üzere, KMO testi 0.927 çıkmıştır. Bu sonuç analiz için iyi bir sonuçtur. 0.927>0.60 olduğundan veri setinin faktör analizi için uygun olduğu görülmektedir. Barlett analizi koşulu da sağlanmaktadır. Veriler faktör analizi için uygundur. Bu istatistik testlerinin faktör analize uygun çıkmış olması nedeniyle, değişkenler arasında korelasyonların yüksek olduğu anlaşılmaktadır. Faktör sayısının belirlenmesi için "Açıklanan Toplam Varyans" yöntemi kullanılmaktadır.

Tablo 11'de görüldüğü üzere, Cronbach's Alfa değeri ise 0.928 çıkmıştır. Bu değer yüksek derecede güvenilir ölçek olarak nitelendirilmektedir. 
Tablo 12. Anti-Images Matrisleri

\begin{tabular}{|c|c|c|c|c|c|c|c|}
\hline & & S10A & $\mathrm{S} 10 \mathrm{C}$ & S10D & S10F & S10G & S10i \\
\hline \multirow{6}{*}{$\begin{array}{l}\text { Anti-image } \\
\text { Covariance }\end{array}$} & $\mathrm{S} 10 \mathrm{~A}$ & .276 & -.023 & -.013 & -.073 & .020 & -.038 \\
\hline & $\mathrm{S} 10 \mathrm{C}$ & -.023 & .215 & .005 & .011 & -.042 & -.018 \\
\hline & S10D & -.013 & .005 & .574 & -.037 & -.199 & -.045 \\
\hline & S10F & -.073 & .011 & -.037 & .435 & .006 & -.073 \\
\hline & S10G & .020 & -.042 & -.199 & .066 & .498 & -.145 \\
\hline & s10i & -.038 & -.018 & -.045 & -.073 & -.145 & .525 \\
\hline \multirow{6}{*}{$\begin{array}{l}\text { Anti-image } \\
\text { Correlation }\end{array}$} & $\mathrm{S} 10 \mathrm{~A}$ & $.932^{a}$ & -.096 & -.033 & -.211 & .054 & -.099 \\
\hline & $\mathrm{S} 10 \mathrm{C}$ & -.096 & $.911^{\mathrm{a}}$ & .015 & .035 & -.130 & -.053 \\
\hline & S10D & -.033 & .015 & $.918^{\mathrm{a}}$ & -.074 & -.373 & -.082 \\
\hline & S10F & -.211 & .035 & -.074 & $.957^{a}$ & .012 & -.152 \\
\hline & S10G & .054 & -.130 & -.373 & .012 & $.894^{a}$ & -.284 \\
\hline & S10i & -.099 & -.053 & -.082 & -.152 & -.284 & $.948^{\circ}$ \\
\hline
\end{tabular}

Tablo 12'te görüleceği üzere, oluşturulan anti-image correlation matrislerinde bileşenlerin örneklem uygunluğu ölçütünün kabul edilebilirlik sınırı olan 0.5 değerinden yüksek olduğu gözlemlenmektedir.

Tablo 13. Ortak Varyans Tablosu

\begin{tabular}{llc}
\hline & Initial & Extraction \\
\hline S10A & 1.000 & .753 \\
\hline S10C & 1.000 & .799 \\
\hline S10D & 1.000 & .429 \\
\hline S10F & 1.000 & .632 \\
\hline S10G & 1.000 & .478 \\
\hline S10i & 1.000 & .528 \\
\hline Extraction Method: Principal Component Analiz
\end{tabular}

Tablo 13'te, her bir faktörün toplam faktörün ne kadarını etkilediği gösterilmektedir. Bu tabloda yer alan "Extraction" değerlerinin, 30 değerinin üzerinde olması beklenmektedir. "Inşaat süreçlerinde oluşan kalite, güvenlik, zaman ve maliyet gibi risklerin azaltılmasını sağlar" faktörü \%79.9 oranı ile toplam faktörü şekillendirmede en çok etkisi olan faktördür. 
DOĞANER, Türkiye'de Sektörel Teknolojik Gelişmelerin Makroekonomi Üzerindeki Etkisi...,55 -76

Tablo 14. Özdeğer İstatistiğine Bağlı Faktör Sayısı ve Açıklanan Varyans Yüzdesi

\begin{tabular}{|c|c|c|c|c|c|c|}
\hline \multirow{2}{*}{ Faktörler } & \multicolumn{3}{|c|}{ Initial Eigenvalues } & \multicolumn{3}{|c|}{ Extraction Sums of Squared Loandings } \\
\hline & Toplam & $\begin{array}{c}(\%) \\
\text { Varyans }\end{array}$ & $\begin{array}{l}\text { Birikimli } \\
\text { (\%) }\end{array}$ & Toplam & $\begin{array}{c}(\%) \\
\text { Varyans }\end{array}$ & Birikimli (\%) \\
\hline 1 & 5.806 & 64.509 & 64.509 & 5.806 & 64.509 & 64.509 \\
\hline 2 & .934 & 10.374 & 74.883 & & & \\
\hline 3 & .515 & 5.717 & 80.600 & & & \\
\hline 4 & .443 & 4.923 & 85.523 & & & \\
\hline 5 & .361 & 4.011 & 89.535 & & & \\
\hline 6 & .341 & 3.792 & 93.327 & & & \\
\hline 7 & .255 & 2.831 & 96.159 & & & \\
\hline 8 & .200 & 2.219 & 98.377 & & & \\
\hline 9 & .146 & 1.623 & 100.000 & & & \\
\hline
\end{tabular}

Birikimli (\%) sütununda faktörlerin yüzde kaç açıkladığı verilmektedir. Tablo 14 'te toplam sütununda yer alan ve özdeğeri 1'den büyük olan faktörler, faktör sayısı olmaktadır. Tablo 14'te verilen değerlerden, faktör sayısının 1 olduğu görülmektedir. 1 adet faktörün varyansa yaptığı katkı \%64.509 oranındadır.

Tablo 14. Faktör Matrisia

\begin{tabular}{lc} 
& Faktörler \\
\cline { 2 - 2 } & 1 \\
\hline S10D & .655 \\
\hline S10C & .894 \\
\hline S10E & .868 \\
\hline S10A & .813 \\
\hline S10F & .795 \\
\hline S10i & .727 \\
\hline S10G & .691 \\
\hline Extraction Method: Principal Component Analiz. a. 1 Components extracted
\end{tabular}

Anket formunda soru $11^{\prime}$ de katılımcılara maliyet açısından değerlendirme yapıldığında, yapay zekanın inşaat sektöründeki hangi alanı en çok etkilediği sorulmuştur. Bu kapsamda, KMO testi ve Barlett Analizi sonuçları Tablo 15'te gösterilmektedir. 
Tablo 15. KMO ve Bartlett Testi

\begin{tabular}{llc}
\hline \multicolumn{2}{c}{ Kaiser-Meyer-Olkin Measure Sampling Adequacy } & .901 \\
\hline \multirow{2}{*}{$\begin{array}{l}\text { Bartlett's Test } \\
\text { of Sphericity }\end{array}$} & Approx.Chi-Square & 515.508 \\
\cline { 2 - 3 } & Df & 28 \\
\cline { 2 - 3 } & Sig. & .000 \\
\hline
\end{tabular}

Tablo 15’te görüldüğü üzere, KMO testi 0.901 çıkmıştır. Bu sonuç analiz için iyi bir sonuçtur. 0.901>0.60 olduğundan veri setinin faktör analizi için uygun olduğu görülmektedir. Barlett analizi koşulu da sağlanmaktadır. Veriler faktör analizi için uygundur. Bu istatistik testlerinin faktör analize uygun çıkmış olması nedeniyle, değişkenler arasında korelasyonların yüksek olduğu anlaşılmaktadır. Faktör sayısının belirlenmesi için "Açıklanan Toplam Varyans" yöntemi kullanılmaktadır.

Tablo 16. Güvenilirlik Analizi

\begin{tabular}{lcc}
\hline $\begin{array}{l}\text { Cronbach's Alpha Based on } \\
\text { Standarized Items }\end{array}$ & $\begin{array}{c}\mathrm{N} \text { of } \\
\text { Items }\end{array}$ & Cronbach's Alfa \\
\hline .904 & 8 & .903 \\
\hline
\end{tabular}

Tablo 16'da görüldüğü üzere, Cronbach's Alfa değeri ise 0.903 çıkmıştır. Bu değer yüksek derecede güvenilir ölçek olarak nitelendirilmektedir.

Tablo 17. Anti-Images Matrisleri

\begin{tabular}{|c|c|c|c|c|c|c|c|c|c|}
\hline & & S11A & S11B & S11C & S11D & S11E & S11F & S11G & $\mathrm{S} 11 \mathrm{H}$ \\
\hline \multirow{8}{*}{$\begin{array}{l}\text { Anti-image } \\
\text { Covariance }\end{array}$} & S11A & .636 & -.022 & -.063 & -.092 & .058 & -.042 & -.126 & -.056 \\
\hline & S11B & -.022 & .505 & -.106 & -.048 & -.040 & -.101 & .029 & -.020 \\
\hline & S11C & -.063 & -.106 & .397 & -.132 & .001 & -.020 & -.088 & -.079 \\
\hline & S11D & -.092 & -.048 & -.132 & .440 & -.099 & .020 & .010 & -.076 \\
\hline & S11E & .058 & -.040 & .001 & -.099 & .345 & -.181 & -.068 & -.005 \\
\hline & S11F & -.042 & -.101 & -.020 & .020 & -.181 & .321 & -.035 & -.067 \\
\hline & S11G & -.126 & .029 & -.088 & .010 & -.068 & -.035 & .540 & -.096 \\
\hline & $\mathrm{S} 11 \mathrm{H}$ & -.056 & -.020 & -.079 & -.076 & -.005 & -.067 & -.096 & .490 \\
\hline \multirow{8}{*}{$\begin{array}{l}\text { Anti-image } \\
\text { Correlation }\end{array}$} & S11A & $.918^{a}$ & -.039 & -.126 & -.173 & .124 & -.093 & -.216 & -.100 \\
\hline & S11B & -.039 & $.932^{a}$ & -.236 & -.101 & -.097 & -.251 & .056 & -.040 \\
\hline & S11C & -.126 & -.236 & $.909^{a}$ & -.315 & .002 & -.057 & -.190 & -.178 \\
\hline & S11D & -.173 & -.101 & -.315 & $.905^{\mathrm{a}}$ & -.253 & .053 & .021 & -.163 \\
\hline & S11E & .124 & -.097 & .002 & -.253 & $.849^{a}$ & -.543 & -.158 & -.012 \\
\hline & S11F & -.093 & -.251 & -.057 & .053 & -.543 & $.858^{a}$ & -.084 & -.168 \\
\hline & S11G & -.216 & .056 & -.190 & .021 & -.158 & -.084 & $.924^{a}$ & -.187 \\
\hline & $\mathrm{S} 11 \mathrm{H}$ & -.100 & -.040 & -.178 & -.163 & -.012 & -.168 & -.187 & $.941^{a}$ \\
\hline
\end{tabular}


Tablo $17^{\prime}$ de görüleceği üzere, oluşturulan anti-image correlation matrislerinde bileşenlerin örneklem uygunluğu ölçütünün kabul edilebilirlik sınırı olan 0.5 değerinden yüksek olduğu gözlemlenmektedir.

Tablo 18. Ortak Varyans Tablosu

\begin{tabular}{llc}
\hline & Initial & Extraction \\
\hline S11A & 1.000 & .425 \\
\hline S11B & 1.000 & .571 \\
\hline S11C & 1.000 & .683 \\
\hline S11D & 1.000 & .635 \\
\hline S11E & 1.000 & .648 \\
\hline S11F & 1.000 & .691 \\
\hline S11G & 1.000 & .543 \\
\hline S11H & 1.000 & .612 \\
\hline
\end{tabular}

Extraction Method: Principal Component Analiz

Tablo 18' de, her bir faktörün toplam faktörün ne kadarını etkilediği gösterilmektedir. Bu tabloda yer alan "Extraction" değerlerinin, 30 değerinin üzerinde olması beklenmektedir. "Inşaat risklerini azaltır (kalite, güvenlik, zaman vb)" faktörü \%69.1 oranı ile toplam faktörü şekillendirmede en çok etkisi olan faktördür.

Tablo 19. Özdeğer İstatistiğine Bağlı Faktör Sayısı ve Açıklanan Varyans Yüzdesi

\begin{tabular}{|c|c|c|c|c|c|c|}
\hline \multirow{2}{*}{ Faktörler } & \multicolumn{3}{|c|}{ Initial Eigenvalues } & \multicolumn{3}{|c|}{ Extraction Sums of Squared Loandings } \\
\hline & Toplam & $\begin{array}{c}\text { (\%) } \\
\text { Varyans }\end{array}$ & $\begin{array}{l}\text { Birikimli } \\
\text { (\%) }\end{array}$ & Toplam & $\begin{array}{c}\text { (\%) } \\
\text { Varyans }\end{array}$ & Birikimli (\%) \\
\hline 1 & 4.808 & 60.099 & 60.099 & 4.808 & 60.099 & 60.099 \\
\hline 2 & .773 & 9.663 & 69.763 & & & \\
\hline 3 & .574 & 7.178 & 76.941 & & & \\
\hline 4 & .495 & 6.191 & 83.132 & & & \\
\hline 5 & .432 & 5.395 & 88.527 & & & \\
\hline 6 & .416 & 5.198 & 93.725 & & & \\
\hline 7 & .298 & 3.731 & 97.456 & & & \\
\hline 8 & .203 & 2.544 & 100.000 & & & \\
\hline
\end{tabular}

Extraction Method: Principal Component Analiz

Birikimli (\%) sütununda faktörlerin yüzde kaç açıkladığı verilmektedir. Tablo $19^{\prime}$ da toplam sütununda yer alan ve özdeğeri 1'den büyük olan faktörler, faktör sayısı olmaktadır. Tablo 
19'da verilen değerlerden, faktör sayısının 1 olduğu görülmektedir. 1 adet faktörün varyansa yaptığı katkı \%60.099 oranındadır.

Tablo 20. Faktör Matrisia

\begin{tabular}{lc}
\hline & Faktörler \\
\cline { 2 - 2 } & 1 \\
\hline S11F & .827 \\
\hline S11E & .652 \\
\hline S11D & .797 \\
\hline S11H & .783 \\
\hline S11G & .737 \\
\hline
\end{tabular}

Extraction Method: Principal Component Analiz. a. 1 Components extracted

Inşaat sektöründe faaliyet gösteren firmaların yapay zeka kavramına bakış açısının belirlenmesi amacıyla oluşturulan örneklem, uygulanan faktör analizi sonucunda aşağıdaki şekilde yorumlanmaktadır. $\left({ }^{*}\right)$ işareti analiz yapılırken faktör yükü 0.30 değerinin altında kalan faktörlerin dışlanması nedeniyle değer oluşmadığı için kullanılmaktadır.

Yapay zeka ile ilgili görüşler

$\mathrm{KMO}=0.817$

Bartlett testi için Ki-kare $=357.497, \mathrm{P}=0.000$

Cronbach's Alpha $=.846$

Toplam varyans açıklama oranı $=\% 61.425$

S9A - Ülkemizde çok yeni (.702)

S9B - İnşaat sektörü için uygun değil (*)

S9C - Maliyet açısından avantaj sağlar (.733)

S9D - İş ve işçi güvenliğine olumlu etkiler sağlar (.710)

S9E - Daha az işçiyle daha çok iş yapılacağından, üretkenlik sağlar (.747)

S9F - İşçilerin yaptıklarıyla aynı etkiyi yaratmaz (.615)

S9G - Kurulumu, bakımı ve onarımı maliyetlidir (.835)

S9H - Etik ve ahlaki değerlere uygun değildir $\left({ }^{*}\right)$

s9i - Diğer $(*)$ 
Yapay zeka ve makine öğrenmesi modellerinin inşaat sektöründe uygulanması halinde gerçekleşecekler

$\mathrm{KMO}=0.927$

Bartlett testi için Ki-kare $=728.296 \mathrm{P}=0.000$

Cronbach's Alpha $=.928$

Toplam varyans açıklama oranı $\% 64.509$

S10A - Öngörülen bütçenin hesaplanmasında ve aşılmamasında kolaylıklar sağlar (.753)

S10B - Bina vb diğer inşaatların planlama, tasarlama, inşa etme ve yönetme konularında kolaylıklar sağlar (*)

S10C - Inşaat süreçlerinde oluşan kalite, güvenlik, zaman ve maliyet gibi risklerin azaltılmasını sağlar (.799)

S10D - Inşaat alanında/şantiyelerde üretken olunması sağlanır (inşaat makinelerinin kullanımı vb konularda) (.429)

S10E - Kaynakların en etkin şekilde kullanılmasını sağlar $\left(^{*}\right)$

S10F - İnşaat güvenliği sağlanır (yapay zeka uygulamaları ile şantiyelerde iş güvenliğine uymayan konular erkenden saptanır

(.632)

S10G - İşgücü sıkıntısının çözülmesini sağlar

(.478)

S1OH - Insan kaynaklı tüm hata ve aksaklıkların önlenmesini sağlar

S10i - Şantiye dışında makineler tarafından inşaatın yapılması, şantiyede montaj yapılması sağlanır $(.528)$

S10J-Diğer $\quad\left(^{*}\right)$

$\mathrm{KMO}=0.915$

Bartlett testi için Ki-kare $=3261.119 \mathrm{P}=0.000$

Cronbach's Alpha $=.940$

Toplam varyans açıklama oranı $=\% 68.306$

S11A - Kullanılan malzemeler, ekipmanlar, bileşenler azalır (.425)

S11B - Proje ve tasarımı kolaylaştırır (.571)

S11C - Elektrik ve sıhhi tesisat gibi yapım aşaması süreçlerini etkiler(tasarım, yapım ve sonrasındaki süreçlerde, BIM) (.683)

S11D - Yapım aşamasındaki anlaşmazlıkları ve aksaklıkları etkiler (.635)

S11E - Şantiye güvenliğinde etkilidir (.648) 
S11F - Inşaat risklerini azaltır (.691)

S11G - İşgücü anlamında sorunları çözer (daha az işgücüne ihtiyaç duyulur) (.543)

$\mathrm{S} 11 \mathrm{H}$ - İnşaatı şantiye dışına taşır (.612)

S11i - Diğer $\left(^{*}\right)$

\section{Tartışma ve Sonuç}

Günümüzde yapay zeka artık her alanda kendini göstermektedir. Bu nedenle, yapay zekanın inşaat sektöründe kullanımı da oldukça önemli ve elzemdir. Günümüzdeki teknolojik gelişmelere uyum sağlamak adına yeniliklerin ve gelişimlerin halihazırdaki gidişatına göre gerekli güncellemelerin, doğru kurgulanmış teknolojik süreçlerin inşaat sektörüne uyumlandırılması gereklidir. Birçok alanda verimlik ve üretkenlik sağlama imkanı olan yapay zeka uygulamalarıyla inşaat sektörünün tanışması ve yaygın olarak kullanımının sağlanması hızı bir şekilde gerçekleştirilmelidir. Ancak süreçlerin inşaat sektörüne uygunluğunun dikkatlice değerlendirilip, nasıl uygun hale getirileceğine dair politikalar da mutlaka önceden düşünülmelidir.

Anket çalışmasında sektörde faaliyet gösteren firmalara yapay zeka ile ilgili görüşleri sorulmuş olup, alınan yanıtlarda en çok kurulumunun, bakımının ve onarımının maliyetli olduğu işaretlenmiştir. Daha sonrasında daha az işçiyle daha çok iş yapılacağından üretkenliğin artacağı, maliyet açısından avantaj sağlayacağı ve ülkemizde çok yeni olduğu şıkları işaretlenmiştir. Yapay zekanın ve makine öğrenmesi modellerinin inşaat sektöründe uygulanması halinde gerçekleşeceklerin sorulduğu soruda ise en çok inşaat süreçlerinde oluşan kalite, güvenlik, zaman ve maliyet gibi risklerin azaltılmasının sağlanacağının belirtildiği şık işaretlenmiştir. Daha sonrasında öngörülen bütçenin hesaplanmasında ve aşılmamasında kolaylıklar sağlanacağı, inşaat güvenliğinin sağlanacağı yani yapay zeka uygulamaları ile şantiyelerde iş güvenliğine uymayan konuların erkenden saptanacağı ve şantiye dışında makineler tarafından inşaatın yapılması, şantiyede montajın yapılmasının sağlanacağını belirtilen şıklar işaretlenmiştir. Diğer soruda ise maliyet açısından değerlendirme yapıldığında yapay zekanın inşaat sektöründeki alanlardan en çok hangisinin etkileneceği sorulmuş olup, alınan cevaplarda en çok inşaat risklerinin azalacağı şıkkı işaretlenmiştir. Daha sonrasında ise elektrik ve sıhhi tesisat gibi yapım aşaması süreçlerini etkileyeceği, şantiye güvenliğinde etkili olduğu, yapım aşamasındaki anlaşmazlıkları ve aksaklıkları etkilediği ve inşaatı şantiye dışına taşıdığını belirten şıklar işaretlenmiştir.

Ülkemizde inşaat sektöründe faaliyet gösteren firmaların büyük çoğunluğu küçük ölçekli 'müteahhit' olarak nitelendirebileceğimiz firmalardan oluşmaktadır. Bu nedenle özellikle 
nitelik anlamında yapay zeka uygulamalarının fayda sağlayacağı, nitelikli elemanlara ihtiyaç duyulacağı da açıktır.

Anket sonuçlarında da görüldüğü gibi, yapay zeka uygulamalarının inşaat sektöründe kullanılmasıyla işlerin daha hızlı, verimli, hatasız olması ve maliyet ve zamandan tasarruf sağlanması mümkün olabilir. Bu nedenle inşaat sektöründe yapay zeka uygulamalarının diğer sektörlerde olduğu gibi kullanılmasının yaygınlaştırılması faydalıdır. Yapay zekanın inşaat sektöründe kullanılması ile daha planlı iş modelleri geliştirilebilecek, üretkenlik artacaktır. Aynı zamanda iş kazalarının oluşma riski azalacak, maliyetler planlı bir şekilde yürütülecektir.

Yapı Bilgi Modellemesi (BIM) yoluyla mimarlar, mühendisler ve diğer projeyle alakalı iş kollarında daha verimli bir tasarım, planlama yapılması sağlanmakta, makine öğrenmesi kullanılarak oluşturulan algoritmalar ile oluşan ya da oluşma ihtimali olan hatalar önceden farkedilebilecektir.

\section{Makalenin Araştırma ve Etik Beyanı Bilgileri}

\begin{tabular}{ll}
$\begin{array}{l}\text { Yazar Çıkar } \\
\text { Çatışması Beyanı }\end{array}$ & $\begin{array}{l}\text { Araştırmaya konu olan durum ve olgular ile yazar arasında herhangi bir } \\
\text { çıar çatışması bulunmamaktadır. }\end{array}$ \\
$\begin{array}{l}\text { Yazar Katkı Oranı } \\
\text { Beyanı }\end{array}$ & $\begin{array}{l}\text { Türkiye'de Sektörel Teknolojik Gelişmelerin Makroekonomi Üzerindeki } \\
\text { Etkisi:Inşaat Sektöründe Yapay Zeka Kullanımına Yönelik Bir İnceleme } \\
\text { isimli makalenin tüm bölümleri tarafımca yazıımıştır. }\end{array}$ \\
\hline $\begin{array}{l}\text { Etik Kurul Onay } \\
\text { Belgesi }\end{array}$ & $\begin{array}{l}\text { Araştırmada kullanılan firma verileri İstanbul Ticaret Odası Meslek } \\
\text { Komiteleri Müdürlüğü'nün 1474 sayı ve 22/01/2020 tarihli müzekkeresi } \\
\text { ile elde edilmiştir. }\end{array}$
\end{tabular}

\section{Kaynakça}

Bayram, N. (2015). Sosyal Bilimlerde SPSS ile Veri Analizi. 5.baskı. Ezgi Kitabevi.

Bilal, M., Oyedele, O. L., Qadir, J., Munir, K., Ajayi, O. S., Akinade, O. O., Oxolabi, A. H. Alaka, A. H., Pasha, M. (2016). "Big Data in the construction industry: A review of present status, opportunities, and future trends". Advanced Engineering Informatics. Vol:30. Issue:3. s.500-521.

Büyüköztürk, Ş. (2002). Sosyal Bilimler İçin Veri Analizi El Kitabı. 28. Ankara: Pegem Akademi yayınları

Currie\&Brown (2018). "Artifical Intelligence in the Construction Industry". Erişim adresi:https://www.curriebrown.com/media/1666/thought-leadershipartificial-intelligence-by-jeremy-newton.pdf.

Değirmenci, C. H., Aydın, İ. H. (2018). "Yapay Zeka”. 1. Baskı Girdap Kitabevi. 
Ekonomik Kalkınma ve İşbirliği Örgütü (2019). "Artifical Intelligence in Society”. Erişim adresi: $\quad$ https://ec.europa.eu/jrc/communities/sites/jrccties/files/eedfee77en.pdf.

Globalnewswire (2019). "Artifical Intelligence (AI) in Construction Market to Reach USD 4.51 Billion By 2026:Reports And Data". Erişim adresi: https://www.globenewswire.com/newsrelease/2019/07/23/1886563/0/en/Artificial-Intelligence-Al-in-ConstructionMarket-to-Reach-USD-4-51-Billion-By-2026-Reports-And-Data.html.

Kalaycı, Ş. (2016). Spss Uygulamalı Çok Değişkenli İstatistik Teknikleri. 7. Baskı. Ankara: Asil Kitabevi.

Korb, K. B., Nicholson, A. E. (2011). "Bayesian Artifical Intelligence”. CRS Press. USA.

Lafrate, Fernardo (2018). "Artifical Intelligence and Big Data, The Birth of a New:Intelligence". Iste Ltd.

McKinsey ve Company Türkiye (2020). "Dijital Çağda Türkiye'nin Yetenek Dönüşümü". Erişim adresi: https://www.mckinsey.com/tr/ /media/McKinsey/Locations/Europe\%20and\% 20Middle\%20East/Turkey/Our\%20Insights/Future\%20of\%20Work\%20Turkey/l simizin-Gelecegi-McKinsey-Turkiye-Raporu-Ocak-2020.ashx.

Mert, M. (2016). Spss, Stata Yatay Kesit Veri Analizi Bilgisayar Uygulamaları. Ankara: Detay Yayınları.

Nilsson, J. N. (2014). "Principles of Artifical Intelligence". Morgan Kaufmann Publishers.

PricewaterhouseCoopers PWC (2017). "Sizing the Prize:What's the Real Value of Al for Your Business and How Can You Capitalise?". Erişim adresi: https://www.pwc.com/gx/en/issues/analytics/assets/pwc-ai-analysis-sizingthe-prize-report.pdf

Salkin, C., Oner, M., Ustündağ A., Cevikcan E. (2017). A Conceptual Framework for Industry 4.0. Industry 4.0:Managing The Digital Transformation. Springer Series in Advanced Manufacturing.

Turan, I.., Şimşek, Ü., Aslan, H. (2015). “Eğitim Araştırmalarında Likert Ölçeği ve Likert Tipi Soruların Kullanımı ve Analizi”. Sakarya Üniversitesi Eğitim Fakültesi Dergisi. Sayı:30.

Türkiye Müteahhitler Birliği (2021). "Inşaat Sektörü Analizi:Salgında Ortak Kaygı;Ekonomi". Erişim adresi: https://www.tmb.org.tr/arastirma yayinlar/tmb bulten nisan2021.pdf 


\title{
The Effect Of Sectoral Technological Developments on Macroeconomic in Turkey: A Review On The Use Of Artifical Intelligence In The Construction Sector
}

\begin{abstract}
Extented Abstract
The construction sector is an important sector which forms infrastructure of the future by directing our country. The construction sector has a positive effect on the economy in terms of macroeconomics as well as being effective in its growth by developing many sub-sectors to which it belongs. Artificial intelligence shows itself in every field. The use of artificial intelligence in the construction sector is very important and essential. In order to adapt to today's technological developments, it is necessary updates and correctly designed technological processes to the current of innovations and developments.
\end{abstract}

\section{Purpose and Significance}

The construction sector has positive effects on macroeconomic balances, especially on economic growth and employment, by positively affecting many sub-sectors to which it is connected. Nowadays, when the benefits of technological developments and concepts such as Industry 4.0 are widely discussed, it is clear that the construction industry should also keep up with innovations and not be left out of the developments. In this study, the effects of artificial intelligence applications, which are quite up-to-date in almost every field, on the construction sector are discussed with their economic dimension.

\section{Method}

In this study, factor analysis was applied to the data obtained as a result of the servuey conducted with companies in order to determine the perspective of construction companies on artifical intelligence apllications and to evaluate their financing and reflections. The survey form (11 questions) of the construction companies registered with the Istanbul Chamber of Commerce was applied to 121 participants. In the questions created in order to get detailed opinions of the participants about artifical intelligence, the "Likert" scale, which has 5 choice answer degrees between "minimum" and "most", was used fort he scale of the questions. It was tried to determine the general tendency in the research questions.

\section{Findings}

In the survey study, the companies operating in the sector were asked their opinions about artificial intelligence, and it was pointed out that the most costly installation, maintenance 
and repair was in the answers received. Then, it is marked that productivity will increase as more work will be done with fewer workers, provide a cost advantage and it is very new in our country. In the questions asking what will happen if artificial intelligence and machine learning models are applied in the construction sector, it is marked that it is stated that the risks such as quality, safety, time and cost that ocur mostly in the constructiın processes will be reduced. Indicated options are marked that it will be facilitated in calculating and not exceeding the foreseen budget, construction safety will be ensured, that is, issues that do not comply with occupational safety in construction sites will be detected early with artificial intelligence applications, the construction is done by the machines outside the consturction site and the assembly is done on the construction site. In the other question, when evaluating in terms of cost, it was asked which of the fields in the construction sector would be most affected by artificial intelligence, and in the answers received, the option that consturction risks would decrease the most was marked. And then, indicated options are marked that it will affect consturtion phase processes such as electrical and plumbing, effective in construction site safety, affecting conflicts and disruptions under construction and moving the construction out of the construction site.

\section{Discussion and Conclusions}

The majority of the companies operating in the construction sector in our country consist of companies that we can describe as small-scale "constractors". For this reason, it is celar that artificial intelligence applications will benefit especially in terms of quality and qualified personnel will be needed. With the use of artificial intelligence applications in the construction industry, it may be possible to make work faster, more efficient, error-free, and to save cost and time. For this reason, it is beneficial to expand the use of artificial intelligence applications in the construction sector as in other sectors. With the use of artificial intelligence in the construction sector, more planned business models will be developed and productivity will increase. At the same time, the occurrence of occupational accidents will be reduced and costs will be carried out in a planned manner. 